\title{
Expression of endothelial cell-specific molecule-1 regulated by hypoxia inducible factor-1 $\alpha$ in human colon carcinoma: Impact of ESM-1 on prognosis and its correlation with clinicopathological features
}

\author{
JOO HEON KIM ${ }^{1}$, MEE YOUNG PARK ${ }^{1}$, CHANG NAM KIM ${ }^{2}$, KYO HYUN KIM ${ }^{3}$, \\ HO BUM KANG ${ }^{4}$, KWANG DONG KIM ${ }^{5}$ and JAE WHA KIM ${ }^{4}$
}

\author{
Departments of ${ }^{1}$ Pathology, ${ }^{2}$ Surgery and ${ }^{3}$ Preventive Medicine, Eulji University School of Medicine, Daejeon 301-070; \\ ${ }^{4}$ Medical Genomics Research Center, Korea Research Institute of Bioscience and Biotechnology, Daejeon 305-333; \\ ${ }^{5}$ Division of Applied Life Science (BK21), PMBBRC, Gyeongsang National University, Jinju 660-701, Republic of Korea
}

Received June 19, 2012; Accepted August 2, 2012

DOI: $10.3892 /$ or.2012.2012

\begin{abstract}
Based on a previous finding that endothelial cellspecific molecule-1 (ESM-1) is a potential serum marker for colorectal cancer (CRC), the aim of this study was to clarify the clinicopathological significance of ESM-1 expression in CRC, and to explore the correlation between ESM-1 and HIF-1 $\alpha$ in the tumorigenesis of CRC related to hypoxic conditions. ESM-1 mRNA expression was examined in CRC and corresponding normal mucosal tissues by reverse transcriptase-polymerase chain reaction (RT-PCR) and realtime RT-PCR. This experiment confirmed that ESM-1 levels were high in CRC. We screened the tissue samples of 143 CRC patients. By immunohistochemistry, we determined that the ESM-1 immunoreactivity was significantly correlated with the tumor size, depth of invasion, nodal status, distant metastasis and Dukes' stage, and was an independent prognostic factor for disease recurrence and worse survival outcome $(\mathrm{P}=0.001)$. The modulation of ESM-1 under hypoxia was investigated, and it was confirmed that ESM-1 expression was induced by HIF1- $\alpha$ and significantly attenuated by small interfering RNA (siRNA) targeting HIF-1 $\alpha$ in CRC cells. These results showed that ESM-1 is significantly overexpressed, which is regulated by HIF-1 $\alpha$ in CRC patients, and can be used as a potential biomarker and a therapeutic target for CRC.
\end{abstract}

Correspondence to: Dr Kwang Dong Kim, Division of Applied Life Science, Gyeongsang National University, 501 Jinju-daero, Jinju 660-701, Republic of Korea

E-mail:kdkim88@gnu.ac.kr

Dr Jae Wha Kim, Medical Genomics Research Center, Korea Research Institute of Bioscience and Biotechnology, P.O. Box 115, Daejeon 305-806, Republic of Korea

E-mail:wjkim@kribb.re.kr

Key words: endothelial cell-specific molecule-1, HIF-1 $\alpha$, hypoxia, immunohistochemistry, colon cancer

\section{Introduction}

Human colon cancer is one of the major causes of morbidity and mortality worldwide. Its tumorigenic mechanism is a multi-step process related to the genetic instability associated with genetic alterations in the invariably less well-oxygenated tumor state (1-6). The unstable hypoxic microenvironment induces the expression of hypoxia inducible factor-1 (HIF1), a key transcriptional regulator which plays a central role in the regulation of biological processes, including glucose metabolism, cell proliferation, angiogenesis, migration, and survival (7-13). HIF-1 $\alpha$ activity is dependent on the localization of HIF-1 $\alpha$ protein in the nucleus (14). Upregulation of the HIF pathway has been shown in aggressive phenotypes of colorectal cancer (CRC) (15-18).

Endothelial cell-specific molecule-1 (ESM-1), also known as endocan, is a $50-\mathrm{kDa}$ secretory proteoglycan, which was originally cloned from a human endothelial cell cDNA library by Lassalle and collaborators (19). The structure of ESM-1 is composed of a mature polypeptide of 165 amino acids and a single dermatan sulfate chain covalently linked to the serine residue at position 137 (19-21). ESM-1 expression in endothelial and epithelial cells is upregulated by tumor necrosis factor (TNF)- $\alpha$, interleukin (IL)-1 $\beta$, and vascular epidermal growth factor (VEGF), downregulated by IL-4 and interferon (IFN)- $\gamma(19,22-24)$, and secreted by vascular endothelial cells, epithelial cells lining distal tubules, bronchi and lung submucosal glands $(19,22,25)$. In addition to ESM-1 expression in normal human tissue, differential expression of ESM-1 has been reported in the vascular endothelium of renal carcinoma (26), breast carcinoma $(27,28)$, glioblastoma (29), non-small cell lung cancer (24), and liver cancer (30). In colon cancer, we reported that ESM-1 expression was increased in the tissue and serum samples of CRC patients, and it can be used as a potential serum marker for early detection of CRC (31). ESM-1 has previously been described to be upregulated by VEGF in vitro and in vivo (20). VEGF is a major target gene of HIF-1 $\alpha$ regulatory genes (32). In addition, Maurage et al showed that 
ESM-1 expression was increased under hypoxic condition (1\% $\mathrm{O}_{2}$ ) in a glioblastoma cell line (29). Although there are several reports that ESM-1 overexpression was closely related to the process of angiogenesis in the endothelial cells from tumor tissues (26,33-35), whether ESM-1 modulation is directly regulated by HIF-1 $\alpha$ or whether the overexpression of these two proteins in the tissue samples of CRC patients significantly correlate with each other has not yet been elucidated.

In this study, we investigated the overexpression of ESM-1 and HIF- $1 \alpha$ in the tissue samples of 143 CRC patients using RT-PCR and immunohistochemistry. Next, the clinicopathological significance of ESM-1 immunoreactivity and its correlation with poor prognosis of CRC was analyzed, and we confirmed the functional inter-correlation of ESM-1 with HIF-1 $\alpha$ in colon cancer cells and tissues.

\section{Materials and methods}

Cell lines and transfection. The human colon cancer cell line, HT29, was purchased from the American Type Culture Collection (ATCC; Rockville, MD, USA). The cells were cultured in Dulbecco's modified Eagle's medium (DMEM; Gibco-BRL, Invitrogen, Carlsbad, CA, USA) supplemented with $2 \mathrm{mM}$ glutamine, $1 \%$ penicillin/streptomycin, and $10 \%$ fetal bovine serum (FBS; Hyclon, Logan, UT, USA), and kept at $37^{\circ} \mathrm{C}$ in a humidified incubator, which was maintained with $5 \% \mathrm{CO}_{2}$. siRNA directed against human HIF-1 $\alpha$ (5'-CUGAU GACCAGCAACUUGATT-3' and 5'-UCAAGUUGCUGGUC AUCAGTT-3') (siGENOME SMARTpool, catalog no. M-013858-00) was purchased from Bioneer (Daejeon, Korea) with its control non-targeting siRNA (catalog no. 1068432), and treated according to the manufacturer's instructions. As an example, 12 pmol of HIF-1 $\alpha$ siRNA was premixed with $15 \mu \mathrm{l}$ of Lipofectamine RNAiMAX reagent (Invitrogen) following the manufacturer's instructions, incubated for $20 \mathrm{~min}$ at room temperature (RT), and used to treat colon cancer cells plated on a $60-\mathrm{mm}$ dish with $40 \%$ confluency. The plasmid-containing wild type HIF-1 $\alpha$-coding region was transfected into the HT29 cell lines using Lipofectamine Plus reagent (Invitrogen), according to the manufacturer's instructions.

Antibodies and western blotting. Cells were washed with phosphate-buffered saline (PBS) and lysed with cell lysis buffer [20 mM Tris-HCl, pH 7.5, $150 \mathrm{mM} \mathrm{NaCl}, 1$ mM EGTA, $1 \mathrm{mM}$ EDTA, 1\% NP-40, $2.5 \mathrm{mM}$ sodium pyrophosphate, $1 \mathrm{mM} \mathrm{Na} \mathrm{VO}_{4}, 1 \mathrm{mM} \mathrm{NaF}$, and Complete Protease Inhibitor Cocktail (Roche, Indianapolis, IN, USA)] on ice for $30 \mathrm{~min}$. SDS-PAGE was used to resolve 30-50 $\mu \mathrm{g}$ of the lysate by using 10 or $12 \%$ gels and transferred to PVDF membranes (Millipore, Billerica, MA, USA). The membranes were incubated with primary antibodies followed by incubation with peroxidase-conjugated anti-rabbit or anti-mouse IgG antibodies (Calbiochem, EMD Chemicals Inc., San Diego, CA, USA) and ECL reagent (Amersham Biosciences Inc., Piscataway, NJ, USA) for band visualization. To verify equal loading and adequate transfer, the membranes were probed with anti- $\gamma$-tubulin antibody (Santa Cruz Biotechnology, Inc., (Santa Cruz, CA, USA). The primary antibodies were antiESM-1 (Abnova, Taipei, Taiwan) and anti-HIF-1 $\alpha$ (Novus Biologicals, Littleton, CO, USA).
RT-PCR analysis. A 2-step RT-PCR reaction was performed using reverse transcriptase with oligo-dT primer, and Taq polymerase (Takara, Shiga, Japan), with specific primer pairs. Total RNA was isolated by a standard protocol (36), and cDNA was synthesized using the AccuScript High Fidelity First Strand cDNA synthesis kit (Stratagene, La Jolla, CA, USA) following the manufacturer's instructions. One microliter of the synthesized cDNA was used per $20 \mu 1$ of PCR reaction mixture, which comprised $0.2 \mathrm{U}$ ExTaq DNA polymerase, $1 \mathrm{X}$ buffer, and $1 \mathrm{mM}$ dNTP mix (Takara), with specific primer pairs, and amplified as follows: 1 cycle of $94^{\circ} \mathrm{C}$ for $5 \mathrm{~min}$; then 30 cycles of $94^{\circ} \mathrm{C}$ for $45 \mathrm{sec}, 56^{\circ} \mathrm{C}$ for $45 \mathrm{sec}$ and $72^{\circ} \mathrm{C}$ for $1 \mathrm{~min}$; followed by a final extension of $7 \mathrm{~min}$ at $72^{\circ} \mathrm{C}$, using the GeneAmp PCR System 2700 (Applied Biosystems, Foster City, CA, USA). PCR primers were designed using the Primer3 program purchased from Bioneer. ESM-1 gene-specific primers used for PCR were 5'-GCCCTTCCTTGGTAGG TAGC-3' (sense) and 5'-TGTTTCCTATGCCCCAGAAC-3' (antisense). The PCR products were separated on a $1.5 \%$ agarose gel, stained with ethidium bromide, visualized by Gel Doc 2000 UV transilluminator (Bio-Rad Laboratories, Hercules, CA, USA), and analyzed using Quantity One software (Bio-Rad Laboratories). Each sample was tested more than 2 times, and the representative data are shown. The primers used for ESM-1 real-time RT-PCR were 5'-AAGGC TGCTGATGTAGTTC-3' (sense), 5'-GCTATTTATGGAAGT GTATGTGTTT-3' (antisense), gapdh; 5'-AGTCAGCCGCAT CTTCTT-3' (sense), 5'-GCCCAATACGACCAAATCC-3' (antisense). Optimized PCR was carried out as follows: 1 cycle of $95^{\circ} \mathrm{C}$ for $10 \mathrm{sec} ; 40$ cycles of $95^{\circ} \mathrm{C}$ for $5 \mathrm{sec}, 60^{\circ} \mathrm{C}$ for $30 \mathrm{sec}$, and $95^{\circ} \mathrm{C}$ for $15 \mathrm{sec}$; and a final extension at $60^{\circ} \mathrm{C}$ for $15 \mathrm{sec}$. The relative levels of gene expression were normalized to GAPDH expression.

Patient samples and immunohistochemistry. Human colorectal carcinoma samples were obtained from patients who underwent routine surgery for colorectal cancer at the Department of Surgery, Eulji University Hospital, between January 2000 and June 2005. Our study protocol (Protocol No. 10-24) was approved by our Institutional Review Board, Eulji University Hospital. For immunohistochemical study, 143 colorectal carcinoma tissue samples and paired normal mucosal tissue samples taken from a site distant from the tumor lesion were fixed in $10 \%$ neutralized-buffered formalin solution for $24 \mathrm{~h}$ and embedded in paraffin wax. Serial sections $(4-\mu \mathrm{m})$ were cut and mounted on charged glass slides (Superfrost Plus; Fisher Scientific, Rochester, NY, USA). IHC conditions for ESM-1 and HIF-1 $\alpha$ were optimized and evaluated by 2 independent pathologists. In brief, tissue sections were microwaved twice for $10 \mathrm{~min}$ in citrate buffer ( $\mathrm{pH}$ 6.0) for antigen retrieval. The sections were then treated with $3 \%$ hydrogen peroxide in methanol to quench the endogenous peroxidase activity, followed by incubation with $1 \%$ BSA. Mouse monoclonal antibodies against ESM-1 (Abnova, Taipei, Taiwan) and HIF-1 $\alpha$ (Novus Biologicals) were used at dilutions of 1:200 and 1:50, respectively. The tissue sections were incubated with antibody overnight at $4^{\circ} \mathrm{C}$ in a wet chamber. The sections were stained using a standard EnVision-HRP kit (Dako, Glostrup, Denmark) and developed with diaminobenzidine as a substrate. An irrelevant mouse $\mathrm{IgG}$ of the same isotype or antibody dilution solution served as a negative control. 
A

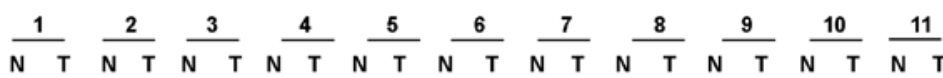

ESM-1

$\begin{array}{llllllllllllllllllllll} & T & N & T & N & T & N & T & N & T & N & T & N & T & N & T & N & T & N & T & N & T\end{array}$

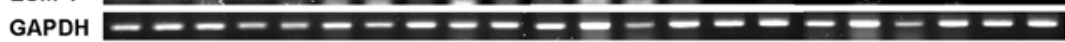

ESM-1

$$
\frac{12}{N} \frac{13}{N} T \frac{14}{N} T \frac{15}{N} \frac{16}{N} \frac{17}{N} \frac{T}{N} \frac{18}{N} \frac{19}{N} \frac{20}{N} \frac{21}{N} T
$$

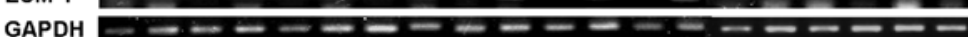

B

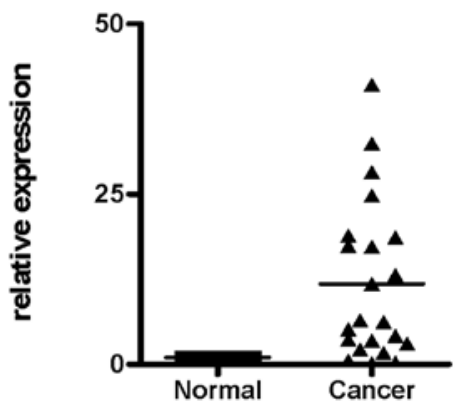

Figure 1. Expression of the ESM-1 gene in human colorectal tissues. (A) In the RT-PCR analysis, comparative expression levels of ESM-1 are shown from 21 normal colon mucosa $(\mathrm{N})$ and colon carcinoma tissue $(\mathrm{T})$ samples. Expression of the ESM-1 gene was higher in the colon carcinoma tissue than that in the corresponding normal mucosa. (B) Real-time RT-PCR analysis was used to determine the level of relative expression of ESM-1 by using the ratio of ESM-1 to GAPDH. The value of tumor-originated ESM-1 was relative to the ESM-1/GAPDH of matched normal controls.

Assessment of immunostaining and statistical analysis. Each slide was evaluated for ESM-1 and HIF-1 $\alpha$ immunoreactivity by using a semi-quantitative scoring system for both the intensity of the stain and the percentage of positive neoplastic cells. In the colorectal and mucosal cells, ESM-1 immunoreactivity corresponded to the cytoplasm and HIF-1 $\alpha$ to the nuclei. The intensity of membrane staining was coded as follows: 0 , weaker than that in the adjacent normal-appearing mucosal epithelium; 1, similar to that in the adjacent mucosal epithelium; and 2 , stronger than that in the adjacent mucosal epithelium. The percentage of cells displaying a stronger staining intensity than that in the adjacent mucosal epithelium was scored as either 1 ( $0-24 \%$ tumor cells stained), 2 (25-49\% tumor cells stained), 3 (50-74\% tumor cells stained), or 4 (75-100\% tumor cells stained). For the purpose of statistical analysis, the median of this series (25\% of malignant cells showing a stronger intensity than adjacent colonic epithelium) was used as a cut-off value to distinguish tumors with low $(<25 \%)$ or high $(>25 \%)$ levels of ESM-1 and HIF-1 $\alpha$ expression. The relationship between the results of the immunohistochemical study and the clinicopathological parameters was determined using the SPSS software package (version 14.0; SPSS Inc., Chicago, IL, USA). The correlation between staining index scores and other categorical factors was analyzed using the Pearson's Chi-square test of independence.

Prognostic parameter for recurrence-free survival and overall survival. Recurrence-free survival was defined as the time from the date of surgery to the first date of recurrence of cancer, or death from any cause. Overall survival was defined as the time from the date of surgery to the date of last follow-up or death from any cause. The median follow-up period for all patients was 54.2 months (inter-quartile range, 23.2-80.7). Survival and median survival curves were estimated using the Kaplan-Meier method. The log-rank test was used to evaluate the statistical significance of differences in survival distribution. Multivariate analysis was carried out using the Cox proportional hazards regression analysis. Results were considered statistically significant if $\mathrm{P}$-values were $<0.05$.

\section{Results}

ESM-1 is differentially expressed in human CRC tissues. To compare the ESM-1 expression levels in the colon cancer tissues, we examined the mRNA level of ESM-1 by performing RT-PCR or real-time RT-PCR analysis on pairs of tissue containing normal and tumor tissue samples from the same donor. GAPDH was used as a reference gene to correct for the variations for mRNA in individual samples. As shown in Fig. 1A and B, 21 cases of colon cancer tissues, randomly selected from clinically diagnosed patients, showed a significant increase in ESM-1 mRNA expression compared to the normal tissue from the same patients.

Hypoxic stress induces ESM-1 expression via HIF-1 $\alpha$ in CRC cells. To investigate the effect of hypoxic stress on ESM-1 expression in colon cancer cells, HT29 cells were exposed to $1 \%$ hypoxia. Under a hypoxic condition, the protein level of HIF $1-\alpha$ was maximized at 8 and $12 \mathrm{~h}$ and was gradually decreased to reach basal level; ESM-1 showed the same trend (Fig. 2A). To test whether ESM-1 induction is correlated with HIF-1 $\alpha$, siRNA targeting HIF-1 $\alpha$ was transfected into HT29 cells and the cells were then incubated for indicated times under a hypoxic condition. siRNA targeting HIF-1 $\alpha$ attenuated the induction of ESM-1 under a hypoxic condition (Fig. 2B). When HIF-1 $\alpha$ was overexpressed in order to confirm whether ESM-1 expression is led by HIF-1 $\alpha$, the expression level of ESM-1 was found to be consistent with that of HIF-1 $\alpha$ (Fig. 2C). Taken together, transcription factor HIF-1 $\alpha$, which is induced under hypoxic conditions, induced ESM-1 expression.

Association of ESM-1 and HIF-1 $\alpha$ expression levels with the clinicopathological characteristics. ESM-1 and HIF-1 $\alpha$ levels were evaluated by immunohistochemical analysis. The elevated expression of ESM-1 and HIF-1 $\alpha$ was detectable in 76 (53.1\%) and 66 (46.1\%) CRC cases, respectively. ESM-1 immunoreactivity was found primarily in the cytosol, but expression of ESM-1 in the cell membrane was occasionally noted in some malignant cells. HIF-1 $\alpha$ was noted predominantly in the nucleus. Fig. 3 shows representative expression patterns of ESM-1 (Fig. 3A and B) and HIF-1 $\alpha$ (Fig. 3C) in CRC tissues. Clinical and pathological characteristics of the $143 \mathrm{CRC}$ patients who underwent surgical resection are summarized in Table I. The median age at the time of surgical resection was 60.3 years. A high level of ESM-1 expression was observed in $76(53.1 \%)$ of the 143 patients. When we tested for an association between the level of ESM-1 expression and the clinicopathological factors potentially predictive of prognosis, 
A

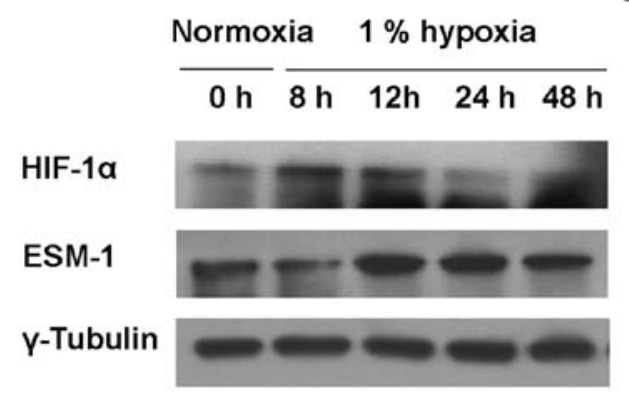

C
B
siHIF-1a

ESM-1

Y-Tubulin

\section{Normoxia $1 \%$ hypoxia}

$0 \mathrm{~h} \quad 8 \mathrm{~h} \quad 12 \mathrm{~h} \quad 24 \mathrm{~h} \quad 48 \mathrm{~h}$
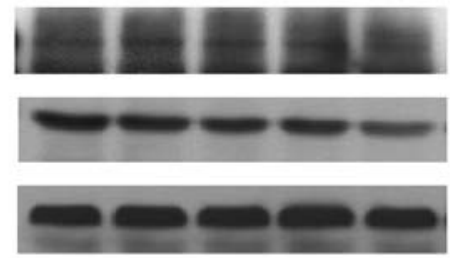

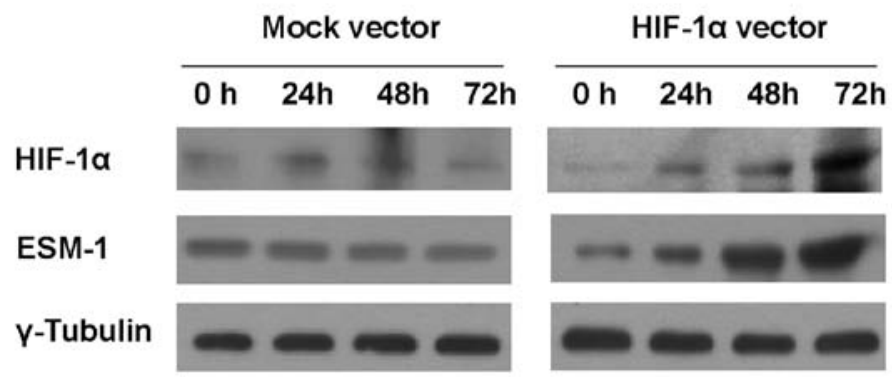

Figure 2. ESM-1 expression is regulated by HIF-1 $\alpha$ induced under hypoxia condition. (A) Human colon cancer cell line HT29 was exposed to hypoxia (1\% oxygen) or normoxia for 3 days. In western blot analysis of HT29 cells, HIF-1 $\alpha$ and ESM-1 overexpression was noted. (B) Downregulation of ESM-1 was induced in the HIF-1 $\alpha$ siRNA-transfected HT29 cells. (C) Modulation of HIF-1 $\alpha$ expression by transfection with a HIF-1 $\alpha$ plasmid vector induced overexpression of ESM-1.
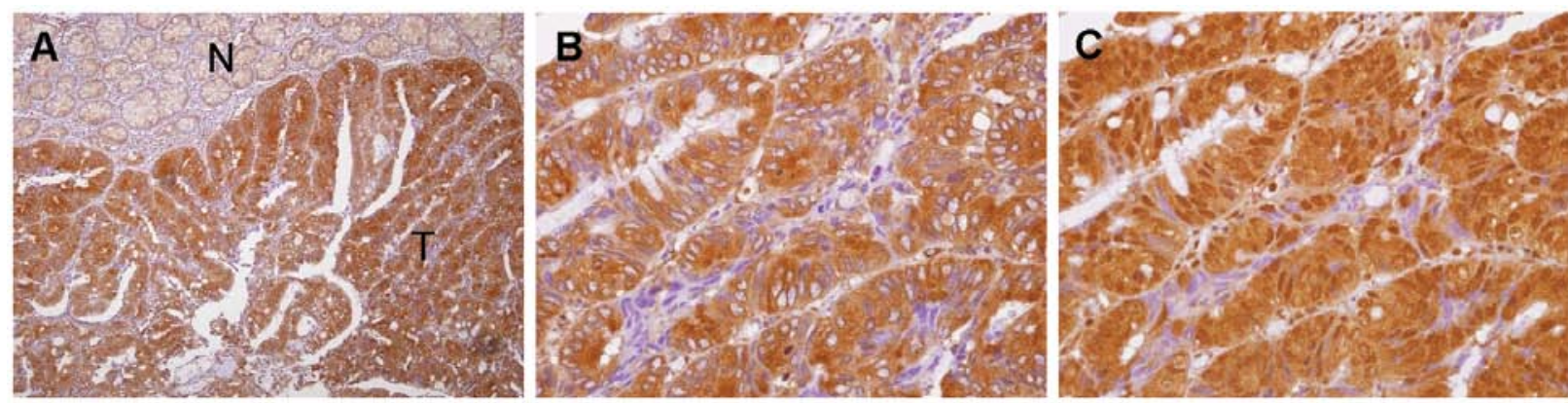

Figure 3. Immunohistochemical expression of ESM-1 and HIF-1 $\alpha$ in human CRC. (A) ESM-1 was highly expressed in the colorectal tumor cells, but not or weakly expressed in the normal colonic mucosa. Original magnification, x40. (B) ESM-1 was strongly expressed primarily in the cytosol of tumor cells. Original magnification, $\mathrm{x} 200$. (C) HIF-1 $\alpha$ was highly expressed in tumor cells of the serial tissue section; it was localized in both the nucleus and the cytosol of tumor cells. Original magnification, $\mathrm{x} 200 . \mathrm{N}$ and $\mathrm{T}$ represent normal and tumor tissue, respectively.

tumor size, depth of invasion, nodal status, distant metastasis, and Dukes' stage, these clinicopathological variables showed a statistically significant association with ESM-1 expression status. We also tested for an association between HIF-1 $\alpha$ status and these variables. A significant correlation between high nuclear HIF-1 $\alpha$ and Dukes' stage $(\mathrm{P}=0.005)$ was noted (data not shown). A significant correlation between high nuclear HIF-1 $\alpha$ and ESM-1 $(\mathrm{P}<0.001)$ was also noted (Table II).

A high level of ESM-1 expression is an independent prognostic factor for disease recurrence and a worse survival outcome. We first carried out univariate analyses to examine whether the expression status of ESM-1 correlates with recurrence-free survival. A total of 40 patients $(28.0 \%)$ presented with recurrence during the follow-up period. At the end of the follow-up, $81(56.6 \%)$ patients were alive, and 62 had died. The analysis showed that a high level of ESM-1 expression was negatively associated with recurrence-free survival $(\mathrm{P}<0.001)$, as shown in Fig. 4A. A high level of ESM-1 expression also correlated significantly with negative overall survival $(\mathrm{P}<0.001)$. Cumulative overall survival curves of patients were significantly split by ESM-1 expression status (Fig. 4B). The mean overall survival times for patients with high and low levels of ESM-1 expression, and all patients were 53.4, 100.4, and 78.1 months, respectively. We carried out multivariate analyses to assess the predictive value of ESM-1 expression status for recurrence-free survival and overall survival by adjusting for other potentially prognostic factors, including age, gender, tumor site, tumor size, cell differentiation and tumor stage. The results corroborated a worse survival outcome in patients with a high level of ESM-1 expression. In a multivariate Cox regression analysis, the independent prognostic factors significantly associated with overall survival were ESM-1 $(\mathrm{P}=0.001)$ and tumor stage $(\mathrm{P}=0.039)$. The relative risk $(\mathrm{RR})$ of death was 
Table I. Clinicopathological variables and the expression status of ESM-1.

\begin{tabular}{|c|c|c|c|c|}
\hline \multirow[b]{3}{*}{ Characteristics } & \multirow[b]{3}{*}{ Total } & \multicolumn{2}{|c|}{ ESM-1 expression level } & \multirow[b]{3}{*}{ P-value } \\
\hline & & Negative/low & High & \\
\hline & & $\mathrm{n}(\%)$ & $\mathrm{n}(\%)$ & \\
\hline \multicolumn{5}{|l|}{ Age (years) } \\
\hline$<50$ & 26 & $12(17.9)$ & $14(18.4)$ & \multirow[t]{2}{*}{0.937} \\
\hline$\geq 50$ & 117 & $55(82.1)$ & $62(81.6)$ & \\
\hline \multicolumn{5}{|l|}{ Gender } \\
\hline Female & 68 & $35(52.2)$ & $33(43.4)$ & \multirow[t]{2}{*}{0.292} \\
\hline Male & 75 & $32(47.8)$ & $43(56.6)$ & \\
\hline \multicolumn{5}{|l|}{ Site } \\
\hline Right/transverse colon & 34 & $14(20.9)$ & $20(26.3)$ & \multirow[t]{2}{*}{0.447} \\
\hline Left colon and rectum & 109 & $53(79.1)$ & $56(73.7)$ & \\
\hline \multicolumn{4}{|l|}{ Size (cm in diameter) } & \multirow[t]{3}{*}{0.030} \\
\hline$<5$ & 61 & $35(52.2)$ & $26(34.2)$ & \\
\hline$\geq 5$ & 82 & $32(47.8)$ & $50(65.8)$ & \\
\hline \multicolumn{5}{|l|}{ Differentiation } \\
\hline Well & 34 & $20(29.9)$ & $14(18.4)$ & \multirow[t]{3}{*}{0.266} \\
\hline Moderately & 82 & $36(53.7)$ & $46(60.5)$ & \\
\hline Poorly & 27 & $11(16.4)$ & $16(21.1)$ & \\
\hline \multicolumn{5}{|l|}{ Depth of invasion } \\
\hline $\mathrm{T} 1$ & 5 & $5(7.5)$ & $\begin{array}{ll}0 & (0.0)\end{array}$ & \multirow[t]{4}{*}{$<0.001$} \\
\hline $\mathrm{T} 2$ & 21 & $16(23.9)$ & $5(6.6)$ & \\
\hline $\mathrm{T} 3$ & 105 & $43(64.2)$ & $62(81.6)$ & \\
\hline $\mathrm{T} 4$ & 12 & $3(4.5)$ & $9(11.8)$ & \\
\hline \multicolumn{5}{|l|}{ Nodal status } \\
\hline No & 67 & $44(65.7)$ & $23(30.3)$ & \multirow[t]{3}{*}{$<0.001$} \\
\hline N1 & 23 & $10(14.9)$ & $13(17.1)$ & \\
\hline $\mathrm{N} 2$ & 53 & $13(19.4)$ & $40(52.6)$ & \\
\hline \multicolumn{5}{|l|}{ Distant metastasis } \\
\hline M0 & 121 & $63(94.0)$ & $58(76.3)$ & \multirow[t]{2}{*}{0.003} \\
\hline M1 & 22 & $4 \quad(6.0)$ & $18(23.7)$ & \\
\hline \multicolumn{5}{|l|}{ Dukes' stage } \\
\hline A & 8 & 7 (10.4) & $1 \quad(1.3)$ & \multirow[t]{4}{*}{$<0.001$} \\
\hline B & 58 & $36(53.7)$ & $22(28.9)$ & \\
\hline $\mathrm{C}$ & 56 & $20(29.9)$ & $36(47.4)$ & \\
\hline $\mathrm{D}$ & 21 & $4(6.0)$ & $17(22.4)$ & \\
\hline
\end{tabular}

more than 3 times higher in patients with high ESM-1 levels (RR, 3.062; 95\% CI, 1.630-5.751) than those with low ESM-1 levels. A high level of ESM-1 expression was also predictive of increased disease recurrence with a P-value of $<0.001$. The RR of disease recurrence for patients with high ESM-1 level was 2.65 (95\% CI, 1.543-4.550). The results from Cox proportional hazards analysis are summarized in Table III.

\section{Discussion}

Intra-tumoral hypoxia is a major event that occurs in most solid tumors $(37,38)$, and HIF is a key transcription factor activating survival machinery in cancer cells under intra-tumoral hypoxic conditions (39). To date, there has been one report suggesting the modulation of ESM-1 expression by hypoxia 
A

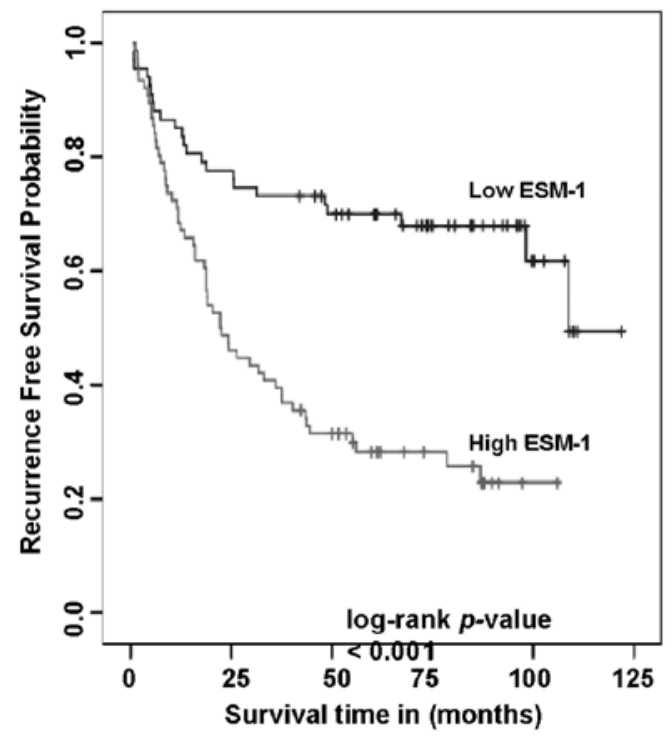

B

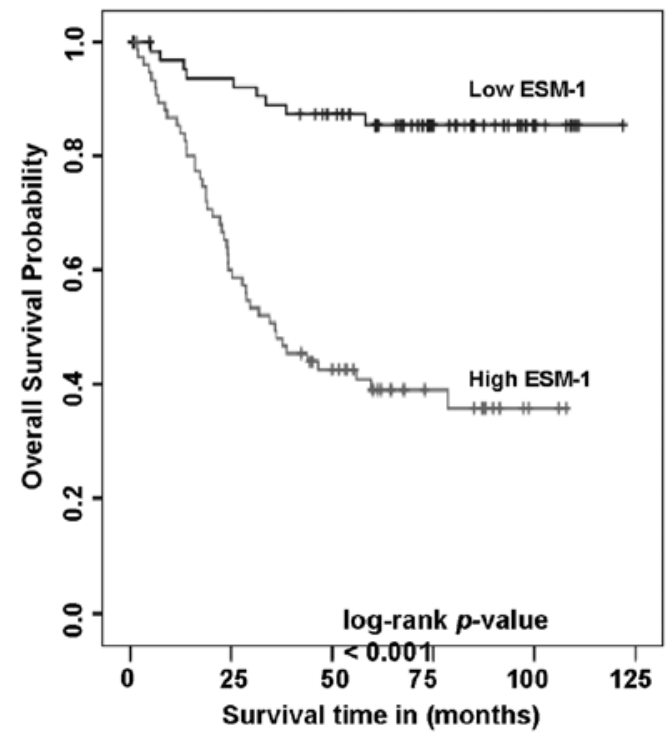

Figure 4. Kaplan-Meier survival analysis by ESM-1 expression status. (A) Cumulative recurrence-free survival differences between patients with high and low ESM-1 expression. (B) Cumulative overall survival differences between patients with high and low ESM-1 expression. The P-value of the difference was obtained using the log-rank test.

Table II. Correlation between ESM-1 and HIF-1 $\alpha$ expression status.

HIF-1 $\alpha$ expression

Frequency Total Low/negative, n (\%) High, n (\%)

ESM-1 expression

\begin{tabular}{llll} 
Low, n (\%) & 67 & $51(76.1)$ & $16(23.9)$ \\
High, n (\%) & 76 & $26(34.2)$ & $50(65.8)$ \\
\hline
\end{tabular}

in human glioblastoma cells in addition to TNF- $\alpha$, fibroblast growth factor (FGF)-2 and VEGF (29). Although we could anticipate the functional correlation of HIF-1 $\alpha$ with ESM-1, there was no in vitro or in vivo evidence to suggest whether there is a significant direct correlation between ESM-1 and HIF-1 $\alpha$. Therefore, in this study, we screened the tissues of 143 CRC patients, and showed that overexpression of ESM-1 in CRC was closely related to the restricted overexpression of HIF-1 $\alpha$ in the nuclei of CRC cells. We also provided the first report that HIF-1 $\alpha$ stimulated the induction of ESM-1 in CRC cells.

ESM-1 has been studied in a number of cell lines and human tumor tissues, and has been shown to influence a variety of normal and pathological processes. ESM-1 is a key player in tumor progression as well as in the regulation of inflammatory disorders $(23,40,41)$, wherein it is either downregulated or overexpressed. In this study, we showed that a high level of cytosolic ESM-1 is an independent and clinically significant prognostic indicator for colon cancer patients who underwent surgery. However, in contradiction to our results, Zuo et al (42) showed that a lower expression of ESM-1 was detected in
CRC tissue compared to that in normal colon and rectal tissue samples, and its expression was positively correlated with tissue differentiation of CRC. Although we could not explain the exact reason why our results differ from those of Zuo et al, we are convinced by our results based on many efforts to confirm our data, including those of a previous published report (31). It is noteworthy that ESM-1 was elevated in the colon cancer cells under hypoxic conditions. Since previous studies showed that HIF-1 $\alpha$ is one of the important regulators in hypoxia, we explored a possible correlation between ESM-1 and HIF-1 $\alpha$ expression status. We showed that ESM-1 was upregulated in the human colon cell line HT29 under $1 \%$ hypoxic conditions, inhibited by siRNA of HIF-1 $\alpha$, and overexpressed following HIF-1 $\alpha$ plasmid vector transfection, suggesting that ESM-1 may be regulated by HIF-1 $\alpha$ in the hypoxic tumor microenvironment during tumor development and progression (27). Indeed, of the 67 tumors containing a high level of nuclear HIF-1 $\alpha$ immunoreactivity, 51 displayed a high level of ESM-1 expression. Of the 76 tumors containing a low level of nuclear HIF-1 $\alpha, 25$ showed a correspondingly low level of ESM-1. The likelihood of observing a high level of ESM-1 expression in a tumor containing a high level of nuclear HIF-1 $\alpha$ was significantly greater than that in a tumor with a low level of nuclear HIF-1 $\alpha(\mathrm{P}<0.01)$. Ji et al recently reported that ESM-1 was secreted in human colon cancer tissue and cells (31). ESM-1 is a novel soluble dermatan sulfate proteoglycan that is secreted from endothelial cells $(19,22)$, and its expression is regulated by tumor cell-derived factors, including vascular endothelial growth factor, in the unstable hypoxic microenvironment (25). This, together with our findings, suggests that ESM-1 may be involved in hypoxia-associated angiogenesis during tumor development and progression.

HIFs are essential mediators in regulating transcription in tumor cells in response to hypoxia $(19,39,43)$. HIF-1 $\alpha$ is 
Table III. Multivariate Cox proportional hazards analysis for recurrence-free and overall survival.

\begin{tabular}{|c|c|c|c|c|c|}
\hline & \multirow[b]{2}{*}{$\mathrm{n}$} & \multicolumn{2}{|c|}{ Recurrence-free survival } & \multicolumn{2}{|c|}{ Overall survival } \\
\hline & & $\mathrm{RR}(95 \% \mathrm{CI})$ & P-value & Median (95\% CI) & P-value \\
\hline \multicolumn{6}{|l|}{ ESM-1 level } \\
\hline Low/negative & 77 & 1.000 & \multirow[t]{2}{*}{0.010} & 1.000 & \multirow[t]{2}{*}{0.001} \\
\hline High & 76 & $2.109(1.196-3.716)$ & & $3.531(1.632-7.644)$ & \\
\hline \multicolumn{6}{|l|}{ Age (years) } \\
\hline$<50$ & 26 & 1.000 . & \multirow[t]{2}{*}{0.900} & 1.000 & \multirow[t]{2}{*}{0.123} \\
\hline$\geq 50$ & 117 & $0.962(0.531-1.744)$ & & $1.862(0.845-4.104)$ & \\
\hline \multicolumn{6}{|l|}{ Gender } \\
\hline Female & 68 & 1.000 & \multirow[t]{2}{*}{0.131} & 1.000 & \multirow[t]{2}{*}{0.387} \\
\hline Male & 75 & $1.432(0.899-2.282)$ & & $1.278(0.733-2.228)$ & \\
\hline \multicolumn{6}{|l|}{ Site } \\
\hline Right colon & 34 & 1.000 & \multirow[t]{2}{*}{0.011} & 1.000 & \multirow[t]{2}{*}{0.096} \\
\hline Left colon & 109 & $2.197(1.195-4.041)$ & & $1.804(0.901-3.612)$ & \\
\hline \multicolumn{6}{|c|}{ Size (cm, diameter) } \\
\hline$<5$ & 61 & 1.000 & \multirow[t]{2}{*}{0.344} & 1.000 . & \multirow[t]{2}{*}{0.104} \\
\hline$\geq 5$ & 82 & $1.27(0.774-2.085)$ & & $1.626(0.905-2.922)$ & \\
\hline \multicolumn{6}{|l|}{ Differentiation } \\
\hline Well & 34 & 1.000 & \multirow[t]{3}{*}{0.236} & 1.000 & \multirow[t]{3}{*}{0.009} \\
\hline Moderately & 81 & $0.771(0.411-1.446)$ & & $0.894(0.404-1.979)$ & \\
\hline Poorly & 28 & $1.299(0.589-2.864)$ & & $2.758(1.100-6.915)$ & \\
\hline \multicolumn{6}{|l|}{ Dukes' stage } \\
\hline $\mathrm{A}$ and $\mathrm{B}$ & 66 & 1.000 & \multirow[t]{2}{*}{0.020} & 1.000 & \multirow[t]{2}{*}{0.039} \\
\hline $\mathrm{C}$ and $\mathrm{D}$ & 77 & $1.942(0.981-3.027)$ & & $2.046(0.846-3.242)$ & \\
\hline
\end{tabular}

P-values were obtained by Cox proportional hazards analysis modeled for the high and low/negative levels of ESM-1 expression.

the most well-characterized, and HIF-2 $\alpha$ (44) has emerged as a non-redundant player, but the role of full-length HIF-3 $\alpha$ $(45,46)$ is not yet known. It is well known that HIF-1 $\alpha$ but not HIF-1 $\beta$ plays an important role in the HIF-1 pathway and regulates HIF target genes (47). HIF-1 $\alpha$ is induced by hypoxia in almost all cell types, and is frequently overexpressed in solid tumors $(11,48)$. Furthermore, the upregulation of HIF-1 $\alpha$ correlates with cancer progression or aggressiveness in many human tumors, although the prognostic significance of HIF-1 $\alpha$ induced by hypoxia in colon cancer has only been restrictively elucidated. Using immunohistochemical screening, we showed that HIF-1 $\alpha$ protein was overexpressed in colon cancer tissues, and that this expression is significantly correlated with Dukes' stage $(\mathrm{P}=0.005)$ and poor overall survival (data not shown). These results were coincident with observations of others that HIF-1 $\alpha$ overexpression is correlated with worse clinical prognosis $(14,49)$.

The present results demonstrated that HIF-1 $\alpha$ enhances ESM-1 expression in response to hypoxia in human CRC. We suggest that ESM-1, in addition to serving as a prognostic marker, may also serve as a therapeutic target by using the HIF pathway in human CRC. Further studies into the potential of ESM-1 inhibition as an effective means of enhancing tumor response to treatment and/or delaying tumor progression are warranted.

\section{Acknowledgements}

This study was supported by a grant of the Korea Healthcare Technology R\&D Project, Ministry for Health, Welfare \& Family Affairs, Republic of Korea (A090509) and by the Next-Generation BioGreen 21 (SSAC, PJ008107), Rural Development Administration, Republic of Korea.

\section{References}

1. Cannito S, Novo E, Compagnone A, et al: Redox mechanisms switch on hypoxia-dependent epithelial-mesenchymal transition in cancer cells. Carcinogenesis 29: 2267-2278, 2008

2. Lluis JM, Buricchi F, Chiarugi P, Morales A and FernandezCheca JC: Dual role of mitochondrial reactive oxygen species in hypoxia signaling: activation of nuclear factor- $\{$ kappa $\} \mathrm{B}$ via c-SRC and oxidant-dependent cell death. Cancer Res 67: 7368-7377, 2007.

3. Sansone P, Piazzi G, Paterini P, et al: Cyclooxygenase-2/carbonic anhydrase-IX up-regulation promotes invasive potential and hypoxia survival in colorectal cancer cells. J Cell Mol Med 13: 3876-3887, 2009. 
4. To KK, Koshiji M,Hammer S and Huang LE: Genetic instability: the dark side of the hypoxic response. Cell Cycle 4: 881-882, 2005.

5. Huang LE, Bindra RS, Glazer PM and Harris AL: Hypoxiainduced genetic instability - a calculated mechanism underlying tumor progression. J Mol Med 85: 139-148, 2007.

6. Bristow RG and Hill RP: Hypoxia and metabolism. Hypoxia, DNA repair and genetic instability. Nat Rev Cancer 8: 180-192, 2008.

7. Yoo YG, Hayashi M, Christensen J and Huang LE: An essential role of the HIF-1alpha-c-Myc ax is in malignant progression. Ann NY Acad Sci 1177: 198-204, 2009.

8. Huang LE, Arany Z, Livingston DM and Bunn HF: Activation of hypoxia-inducible transcription factor depends primarily upon redox-sensitive stabilization of its alpha subunit. J Biol Chem 271: 32253-32259, 1996.

9. Maynard MA and Ohh M: The role of hypoxia-inducible factors in cancer. Cell Mol Life Sci 64: 2170-2180, 2007.

10. Harris AL: Hypoxia - a key regulatory factor in tumour growth. Nat Rev Cancer 2: 38-47, 2002.

11. Brahimi-Horn MC, Chiche J and Pouyssegur J: Hypoxia and cancer. J Mol Med 85: 1301-1307, 2007.

12. Brahimi-Horn MC and Pouyssegur J: Hypoxia in cancer cell metabolism and $\mathrm{pH}$ regulation. Essays Biochem 43: 165-178, 2007.

13. Brahimi-Horn MC, Chiche $\mathrm{J}$ and Pouyssegur J: Hypoxia signalling controls metabolic demand. Curr Opin Cell Biol 19: 223-229, 2007.

14. Brahimi-Horn MC and Pouyssegur J: HIF at a glance. J Cell Sci 122: 1055-1057, 2009.

15. Koukourakis MI, Giatromanolaki A, Simopoulos C, Polychronidis A and Sivridis E: Lactate dehydrogenase 5 (LDH5) relates to up-regulated hypoxia inducible factor pathway and metastasis in colorectal cancer. Clin Exp Metastasis 22: 25-30, 2005.

16. Sivridis E, Giatromanolaki A and Koukourakis MI: Proliferating fibroblasts at the invading tumour edge of colorectal adenocarcinomas are associated with endogenous markers of hypoxia, acidity, and oxidative stress. J Clin Pathol 58: 1033-1038, 2005.

17. Giles RH, Lolkema MP, Snijckers CM, et al: Interplay between VHL/HIF1alpha and Wnt/beta-catenin pathways during colorectal tumorigenesis. Oncogene 25: 3065-3070, 2006.

18. Koukourakis MI, Giatromanolaki A, Polychronidis A, et al: Endogenous markers of hypoxia/anaerobic metabolism and anemia in primary colorectal cancer. Cancer Sci 97: 582-588, 2006.

19. Lassalle P, Molet S, Janin A, et al: ESM-1 is a novel human endothelial cell-specific molecule expressed in lung and regulated by cytokines. J Biol Chem 271: 20458-20464, 1996.

20. Sarrazin S, Adam E, Lyon M, et al: Endocan or endothelial cell specific molecule-1 (ESM-1): a potential novel endothelial cell marker and a new target for cancer therapy. Biochim Biophys Acta 1765: 25-37, 2006

21. Bechard D, Scherpereel A, Hammad H, et al: Human endothelial-cell specific molecule-1 binds directly to the integrin CD11a/ CD18 (LFA-1) and blocks binding to intercellular adhesion molecule-1. J Immunol 167: 3099-3106, 2001.

22. Bechard D, Meignin V, Scherpereel A, et al: Characterization of the secreted form of endothelial-cell-specific molecule 1 by specific monoclonal antibodies. J Vasc Res 37: 417-425, 2000.

23. Scherpereel A, Depontieu F, Grigoriu B, et al: Endocan, a new endothelial marker in human sepsis. Crit Care Med 34: 532-537, 2006.

24. Grigoriu BD, Depontieu F, Scherpereel A, et al: Endocan expression and relationship with survival in human non-small cell lung cancer. Clin Cancer Res 12: 4575-4582, 2006.

25. Abid MR, Yi X, Yano K, Shih SC and Aird WC: Vascular endocan is preferentially expressed in tumor endothelium. Microvasc Res 72: $136-145,2006$

26. Leroy X, Aubert S, Zini L, et al: Vascular endocan (ESM-1) is markedly overexpressed in clear cell renal cell carcinoma. Histopathology 56: 180-187, 2010.
27. Aitkenhead M, Wang SJ, Nakatsu MN, Mestas J, Heard C and Hughes CC: Identification of endothelial cell genes expressed in an in vitro model of angiogenesis: induction of ESM-1, (beta) ig-h3, and NrCAM. Microvasc Res 63: 159-171, 2002.

28. Song Q, Jing H, Wu H, Zhou G, Kajiyama T and Kambara $H$ Gene expression analysis on a photodiode array-based bioluminescence analyzer by using sensitivity-improved SRPP. Analyst 135: 1315-1319, 2010.

29. Maurage CA, Adam E, Mineo JF, et al: Endocan expression and localization in human glioblastomas. J Neuropathol Exp Neurol 68: 633-641, 2009.

30. Kang YH, Ji NY, Lee CI, et al: ESM-1 silencing decreased cell survival, migration, and invasion and modulated cell cycle progression in hepatocellular carcinoma. Amino Acids 40: 1003-1013, 2010

31. Ji NY, Kim YH, Jang YJ, et al: Identification of endothelial cellspecific molecule-1 as a potential serum marker for colorectal cancer. Cancer Sci 101: 2248-2253, 2010.

32. Semenza GL: Targeting HIF-1 for cancer therapy. Nat Rev Cancer 3: 721-732, 2003.

33. Chen LY, Liu X, Wang SL and Qin CY: Over-expression of the endocan gene in endothelial cells from hepatocellular carcinoma is associated with angiogenesis and tumour invasion. J Int Med Res 38: 498-510, 2010.

34. Rennel E, Mellberg S, Dimberg A, et al: Endocan is a VEGF-A and PI3K regulated gene with increased expression in human renal cancer. Exp Cell Res 313: 1285-1294, 2007.

35. Bechard D, Gentina T, Delehedde M, et al: Endocan is a novel chondroitin sulfate/dermatan sulfate proteoglycan that promotes hepatocyte growth factor/scatter factor mitogenic activity. J Biol Chem 276: 48341-48349, 2001.

36. Chomczynski P and Sacchi N: Single-step method of RNA isolation by acid guanidinium thiocyanate-phenol-chloroform extraction. Anal Biochem 162: 156-159, 1987.

37. Hockel M and Vaupel P: Biological consequences of tumor hypoxia. Semin Oncol 28: 36-41, 2001.

38. Foo SS, Abbott DF, Lawrentschuk N and Scott AM: Functional imaging of intratumoral hypoxia. Mol Imaging Biol 6: 291-305, 2004.

39. Mabjeesh NJ and Amir S: Hypoxia-inducible factor (HIF) in human tumorigenesis. Histol Histopathol 22: 559-572, 2007.

40. Filep JG: Endocan or endothelial cell-specific molecule-1: a novel prognostic marker of sepsis? Crit Care Med 34: 574-575, 2006.

41. Sarrazin S, Lyon M, Deakin JA, et al: Characterization and binding activity of the chondroitin/dermatan sulfate chain from endocan, a soluble endothelial proteoglycan. Glycobiology 20: $1380-1388,2010$

42. Zuo L, Zhang SM, Hu RL, et al: Correlation between expression and differentiation of endocan in colorectal cancer. World J Gastroenterol 14: 4562-4568, 2008.

43. Ryan HE, Poloni M, McNulty W, et al: Hypoxia-inducible factorlalpha is a positive factor in solid tumor growth. Cancer Res 60: 4010-4015, 2000.

44. Swami M: Hypoxia: the HIF2alpha puzzle. Nat Rev Cancer 10: 603,2010

45. Gu YZ, Moran SM, Hogenesch JB, Wartman L and Bradfield CA: Molecular characterization and chromosomal localization of a third alpha-class hypoxia inducible factor subunit, HIF3alpha. Gene Expr 7: 205-213, 1998.

46. Kietzmann T, Cornesse Y, Brechtel K, Modaressi S and Jungermann K: Perivenous expression of the mRNA of the three hypoxia-inducible factor alpha-subunits, HIF1alpha, HIF2alpha and HIF3alpha, in rat liver. Biochem J 354: 531-537, 2001.

47. Clottes E: Hypoxia-inducible factor 1: regulation, involvement in carcinogenesis and target for anticancer therapy. Bull Cancer 92: 119-127, 2005 (In French).

48. Zhong H, De Marzo AM, Laughner E, et al: Overexpression of hypoxia-inducible factor 1alpha in common human cancers and their metastases. Cancer Res 59: 5830-5835, 1999.

49. Baba Y, Nosho K, Shima K, et al: HIF1A overexpression is associated with poor prognosis in a cohort of 731 colorectal cancers. Am J Pathol 176: 2292-2301, 2010. 